REVIEW

\title{
Contextualizing Ottawa Charter Frameworks for Type 2 Diabetes Prevention: A Professional Perspective as a Review
}

\author{
Feleke Doyore Agide $^{1,2}$, Elham Shakibazadeh ${ }^{3 *}$
}

\section{OPEN ACCESS}

Citation: Feleke Doyore Agide, Elham Shakibazadeh. Contextualizing Ottawa Charter Frameworks for Type 2 Diabetes Prevention: A Professional Perspective as a Review. Ethiop J Health Sci.2017;28(3):355.

doi:http://dx.doi.org/10.4314/ejhs.v28i3.14

Received: November 28, 2017

Accepted: November 29, 2017

Published: May 1, 2018

Copyright: (C) 2018 Feleke D. et al . This is an open access article distributed under the terms of the Creative Commons Attribution License, which permits unrestricted use, distribution, and reproduction in any medium, provided the original author and source are credited.

Funding: Nil

Competing Interests: The authors declare that this manuscript was approved by all authors in its form and that no competing interest exists.

Affiliation and Correspondence:

${ }^{1}$ Department of Health Education and Promotion, School of Public Health, International Campus, Tehran University of Medical Sciences, Tehran, Iran

${ }^{2}$ Department of Public Health Officer, College of Medicine and Health Sciences, Wachemo University, Hossana, Ethiopia

${ }^{3}$ Department of Health Education and Promotion, School of Public

Health, Tehran University of

Medical Sciences, Tehran, Iran

*Email: shakibazadeh@tums.ac.ir
ABSTRACT

BACKGROUND: Type 2 Diabetes remains one of the deadliest non-communicable diseases in the world. Systematically articulating the health issues with emerging policies is very important in preventing chronic diseases like diabetes. This article aims to integrate Ottawa Charter frameworks in prevention of Type 2 diabetes and the way the charter's application should bring amicable changes if applied as planned.

METHOD: We used the aim of the study as a method derivative. Then, we applied the five actions of Ottawa Charter frameworks. We also described and stated the existing scientific literature (knowledge) about the prevention of diabetes. After thoroughly reviewing, possible intervention strategies were included with a brief discussion by comparing different literatures. In our case, diabetes prevention is facilitated by those actions and conditions.

EVIDENCE: Setting appropriate goals, lifestyle modifications, appropriate self-monitoring of blood glucose, medications, regular monitoring for complications, and laboratory assessment are important factors to be endorsed within Ottawa Charter five actions. Lifestyle interventions and physical activities are the most important factors recommended in different reviews and interventions. However, none of the studies had integrated disease prevention with existing policy.

CONCLUSION: Type 2 Diabetes directed health promotion interventions implemented in various countries were not integrated into Ottawa charter frameworks. As field experts, we believe that applying all the basic principles of health promotion and the idea of Ottawa Charter articulation is very important in disease prevention and behavioral change. Therefore, field specialists should figure out the problem of policy integration through policy evaluation researches.

KEYWORDS: Contextualizing, Diabetes, Health Promotion, Ottawa Charter 


\section{INTRODUCTION}

Ottawa Charter is a response to the growing expectations of a new public health movement to integrate health in all policies. The agreement made entitled to 'Ottawa Charter for health promotion' introduced significant changes in the growth and development of the field of health promotion and health policies across the globe (13 ). Health for all is a major societal goal of governments and the cornerstone of sustainable development that comes across to our future. To this end, the Millennium Development Goals (MDGs) have been in the background of much of the global efforts on health. However, they were not explicitly directed to the causes of poor health as in the public health sector aspiration. The concepts of health in all policies (HiAP), the social determinants of health (SDH) and governance front and center with particular emphasis on the global impact of noncommunicable diseases (NCDs) are considered as the main pillars to be addressed (4).

The global burden of NCDs is enormous being serious in the developing world due to the double burden of infectious conditions. The chronic NCDs predisposing factors are driven by a combination of demographic changes, increasing urbanization, lifestyle modifications and economic growth. The factors can be marked as behavioral, environmental, policy, demographic, lifestyle choices like smoking, nutrition, and physical inactivity. These factors explain why the burden of NCDs is expected to grow unless the world set an integrated effort for the prevention and control (5).

Diabetes mellitus is increasingly becoming a major public health problem in low- and middleincome countries $(5,6)$. The prevalence of diabetes is increasing worldwide due to an aging population and increased rates of obesity (6). It is a rising global concern as a result of its life-long disease nature and challenging epidemiology $(6,7)$. The estimated case of more than 415 million adults worldwide in 2015, is expected to rise to 642 million cases by $2040(8,9)$. In low- and middle-income countries, roughly, 4 out of 5 people live with diabetes that indicates the incidence is increasing in every country and becomes the most considered cause of morbidity and mortality worldwide (10). Thus, the aim of this paper is to contextualize Ottawa Charter frameworks in diabetic disease prevention and to demonstrate how the charter's application brings amicable changes if applied as planned.

\section{MATERIALS AND METHODS}

We used the aim of the study as a method derivative. The aim is simply applying Ottawa Charter frameworks in Type 2 Diabetes (T2DM) prevention. For this, we described and stated the existing scientific literatures (knowledge) about the prevention of diabetes and applied the Ottawa Charter frameworks of five actions. After thoroughly reviewing the recently available literature on the charter's framework applications and health promotion development techniques, possible intervention strategies were suggested with a brief discussion, not in deep, by comparing them.

\section{Ottawa Charter Frameworks}

Building public health policy: The importance of well-framed and problem-solving objectives is intuitively known by all scholars. The Ottawa Charter for Health Promotion guides health promotion practice to consider multi-level strategies at individual, community and system levels to address complex issues and achieve sustainable changes (11). The role of political influence on the strategies that are implemented and the opportunities for evaluation cannot, however, be ignored. A balance must be achieved between a quick response to a health issue that magnetizes public concern and undertaking sufficient planning to ensure the response. In a consensus study, with the aim of defining sustainable community-based health promotion practice, practitioners highlighted four key features, namely: effective relationships and partnerships, building community capacity, evidence-based decision-making and practice and a supportive context for practice (12). Reactive

DOI: http://dx.doi.org/10.4314/ejhs.v28i3.14 
responses may be justified if implemented as part of a more comprehensive, evidence-based and theory-based health promotion strategy (12-14). A significant prevention action should be added to address prevention of diseases in general and T2DM in particular to give a quick response and to develop locally important strategies for lifestyle modification and self-management. In reality, the governments of various countries, where the disease is their concern, are working very well and giving political meanings as well (12). However, politicians look things on the side of politics and reshuffle the idea to their political benefits and quick responses to public health concerns. To this end, working with disparate communities and marginalized populations may be ignored in the urgency to act quickly. As a result, disease prevention in these groups may wage high human and financial costs or may be sought to kenistic at best, with the increased risk of disease occurrence and lacking social capital and support (15). There is also some reluctance among practitioners to evaluate health promotion programs due to the potential risk of unfavorable findings. Still, reporting advantages and disadvantages with integrated outcomes are very important, not to commit the same mistake again since others learned the lessons from previous one. Confidence to disseminate the learnings to targeted audiences and the large society mainly depends on the commitment of program planners and the availability of resources (16-18).

Creating supportive environment: Evidence of the synthesis of seventeen studies indicated that diabetes prevention programs (DPPs) can be used to deliver outcomes of increased weight loss to reduce diabetes risk $(17,19)$. Yet, participation by those at risk can be problematic (19). For example, a study of 89 European women evaluated the effectiveness of an established lifestyle intervention in comparison to standard care for delaying diabetes onset in women who had recent gestational diabetes mellitus (20). The risk factors analyzed included smoking, fruit/vegetable intake, exercise, family history of diabetes, glucose values, body mass index (BMI), use of insulin during pregnancy, and age at delivery. Integrating public health and healthcare services through a formal governance structure creates opportunities for the traditionally ignored functions to develop shared goals, consider comprehensive intervention strategies, and identify ways that their services can be complementary (14). In addition, shared governance is a way of raising awareness of public health resources and functions among clinical providers. One way to create such a structure for healthcare providers is to include public health representative(s) on a governing entity's board, providing public health officials with a meaningful role in directing the board's strategies and priorities. The board's governance documents may also include a commitment to engaging with the state or county public health department to implement prevention initiatives aimed at improving the health of its members and the broader community. As part of the governing body, public health officials are assigned to play an important role in helping providers think about the long-term returns on investment in primary and secondary prevention $(16,18,20)$. Furthermore, creating supportive environment is used for identifying organizations that may assist in understanding the features of various strategies and practices needed to overcome common barriers to disease prevention (20).

Developing personal skills: T2DM health promotion programs are particularly important to prevent unintended effects. Yet, the reality for agencies undertaking health promotion work is that evaluation may not be well understood by staff, even those with a health promotion or public health background. Enabling people to learn, throughout life, to prepare them for all of its stages and to cope with chronic illness and injuries is essential. This has to be facilitated in school, home, work and community settings. An action is required through educational, professional, commercial and voluntary bodies, and within the institutions themselves (21).

Health promotion supports personal and social development through providing information, education for health, and enhancing life skills for any diseases prevention in general and diabetes in particular. By so doing, it increases the options available to people to exercise more control over their own health and over their

DOI: http://dx.doi.org/10.4314/ejhs.v28i3.14 
environments, and to make choices conducive to health. Notable are the words 'information, education and enhancing'. These are three distinct ideas: information is a rather passive concept, education is about learning and skills are tools that an individual takes on. The next sentence is an 'evidence statement' that can be evaluated as in 'it increases the options available to people to exercise more control over their own health and over their environments, and to make choices conducive to health'. Such statements are often made as if they are truisms, however, in reality; they set up the possibility for misrepresentation (22). This is apparent because of the use of the word 'essential'. Furthermore, the whole statement implies that this value can be carried out through action in particular settings. There are, of course, many settings, but the Charter specifies school, home, work, and community. There are physical places and community, of course, may be understood as both a physical and/or a conceptual idea. Given the placement in the text, it would imply a physical setting; however, as health promotion developed in the last 25 years, the concept of community became far more variant and complex (23). Therefore, according to several studies, individuals, groups and communities should focus on developing skills like choosing foods, diets, daily recommended allowances, physical activities, and life styles modification and self-management (24-26).

Strengthen community actions: Diabetes prevention works through concrete and effective community action in setting priorities, making decisions, planning strategies and implementing them to achieve better health. At the heart of this process is the empowerment of communities-their ownership and control of their own endeavors and destinies (22).

Reorient health services: The responsibility for health promotion in health services is shared among individuals, community groups, health professionals, health service institutions, and governments (11). They must work together towards a healthcare system which contributes to the pursuit of health. The role of the health sector should move more and more in an exceeding health promotion direction, beyond its responsibility for providing clinical and curative services. Health promotion services in diabetes prevention should be integrated by streamlining with alternative health services and decentralizing the issue into community and grass root levels. Health services need to embrace an expanded mandate which is sensitive and respects cultural desires. This mandate should support the requirements of individuals and communities for a healthier life, and open channels between the health sector and the broader social, political, economic, and physical environmental components. Reorienting health services also requires stronger attention to health research as well as changes in professional education and training. This should lead to a change of attitude and organization of health services which refocuses on the total needs of the individuals as a whole $(11,21,26)$.

Therefore, going in the long run, health should create and live by people within the settings of their everyday life; wherever they learn, work, play and love. Furthermore, health can be achieved through caring one for the others, by being able to take decisions and have management over one's life circumstances. This, in turn, ensures that the society lives in a conducive environment that allow the attainment of health in all areas (11).

\section{EVIDENCES}

Studies on Diabetes prevention interventions: The reviews published by Van den Berg $\mathrm{M}$ et al. and Foster C.et al. on transitional interventions indicated that diabetes prevention varies in its application and effectiveness $(27,28)$. Health promotion interventions project in Norway stated that interventions targeted dietary education, selfmanagement and psychological support have a significant impact on prevention of the diseases. The initiatives targeting healthcare professionals or community stakeholders had a great contribution on the program accomplishement. This project also mentioned that patient empowerment is a significant factor which helps

DOI: http://dx.doi.org/10.4314/ejhs.v28i3.14 
for lifestyle modifications (29). For instance, Thomas D. et al. in theirs ystematic review of the effects of exercise on T2DM parameters showed that increased levels of physical activity had a positive effect on the prevention of T2DM (30).

Duke SAS et al., Attridge M.et al. and Dorresteijn JA et al., in their systematic reviews of the effectiveness of educational interventions for individuals with diabetes, indicated that management of blood glucose, blood pressure, body mass index, and cholesterol had a significant impact on prevention and control of the diseases. In the same studies, self-efficacy and empowerment of the patient regarding disease control, knowledge on T2DM, smoking cessation, self-management concerning diet and psychosocial outcomes had significant effect on prevention of diabetes. Foot care and prevention of fungal infections had contributed for prevention and control of the diseases (31-33).

Dunkley AJ, et al., in their systematic review and meta-analysis of the effectiveness of lifestyle interventions for the prevention of T2DM, had significantly associated with a greater weight loss. Though the authors focused on translational studies in relation to the main outcome rather than giving further explanation, the study showed a significant impact on prevention and control of diabetes (34). Another systematic review of realworld diabetes prevention programs interventions on program participation and program effectiveness by Aziz Z, et al., suggested that while a high-frequency intervention plays an important role in achieving high weight loss outcomes, programs with 'low'-intense interventions have also shown high reductions in the incidence of T2DM (35).

Interventions to promote physical activity in people with T2DM had shown a significant effect in increasing level of physical activities. However, most studies focused on middle-aged persons had no significant effect of diseases, and there was lack of well-designed trials $(36,37)$.
Interventions suggested by authors after thorough contextualizing

Interventions that build health public policy:

- Campaigning to extend the coverage of optimal low fat foods and carbonates;

- Supporting early childhood centres and school boards in developing healthy food and nutrition policies;

- Working to ensure that diabetes care is included in residential care accreditation schemes;

- Working on policy options that eliminate the advertising of harmful food and beverages to adults and children;

- Working with organizations to promote physical activity, good nutrition, sedentary life prevention policies, for example, sport days and gymnastics places in schools;

- Working with industry to reduce the marketing of sugar-containing drinks or to develop standards for marketing to diabetes patients; and

- Supporting the implementation of policies that create smoke-free environments.

\section{Interventions that create supportive} environments for diabetes prevention"

- Providing subsidies to promote access to low fat foods and reduced sugar drinking;

- Supporting healthy supermarket practice, for example, removing sweets from checkout displays;

- Encouraging the use of salt and sugar-free environment advertising and sponsorship to promote health;

- Including diabetes condition/health in media advertising about healthy food choices;

- Promoting social marketing campaigns that aim to raise NCDs health awareness; and

- Promoting sponsorship ethics, for example, healthy fundraising options. 
Interventions to develop personal skills for diabetes prevention:

- Promoting regular self-care with physical exercise, regular monitoring blood sugar level;

- Health professionals' opportunistically discussing diabetes prevention session;

- Including diabetic diseases in health messages in education programmes and materials focused on good nutrition; and

- Working with sports organizations to ensure that exercise should include weight loss and balance body weights.

Interventions that strengthen community action for diabetes prevention:

- Engaging the community to support in life style modification especially in physical activities and weight loss;

- Developing preschool and primary school physical activities with community participation and leadership in high-need areas;

- Developing healthy eating programmes that support body balance and normal weight;

- Supporting the development of community-led and culturally appropriate health services; and

- Working with community groups to advocate for healthy playgrounds with safe life styles.

Interventions to re-orientate health services for disease prevention:

- Supporting the development of communitybased life style modification promoters;

- Collaborating with non-governmental organizations, public health organizations and social services in planning NCDs prevention services;

- Promoting linked enrolment between public health organizations and diabetes prevention health services;

- Increasing the preventive context components of training for health professionals; and

- Developing policies that support on-going access to health care.

\section{DISCUSSION}

The aim of this article is not meant to replace or criticize the existing frameworks and planning models that focus on the best match of the program. The article adds value to the prevailing structures and frameworks, designs, methods, approaches and resources in reminding those who design health promotion programs fit specific diseases like diabetes (T2DM).

In terms of applicability, health promotion programs have unique options unlike other health programs in their settings, scales, approaches, strategies and contexts. Discussing the health promotion issues with the integration of disease prevention using existing and harmonious frameworks makes the program more successful. However, the application of the program through understanding multiple factors and policies is incredibly low and not context-specific in numerous countries (38-39).

Since the nature of T2DM needs the modification of individuals, environmental, behavioral, and education paradigms, there is a desire to articulate these issues with existing policies. Australian authors confirmed the importance of this concept in disease prevention and health promotion actions like HIV/AIDS, smoking, and road safety (38). This is because of the appropriate interlink of Ottawa Charter with health promotion actions mainly streamlining with health public policies, community participation, and population-wide education strategies is taken as an umbrella $(38,39)$.

According to Saan and Wise, one of the Ottawa Charter merits is its action areas form an interlinked theoretical framework (40). Disease prevention and Ottawa Charter are extremely interactive and interdependent processes acting in mutually contributing and reinforcing ways (41). Applying public health policy is used as a general component which facilitates other Ottawa Charter actions to be endorsed, which increases the likelihood of diseases prevention in general and diabetes in particular. The interdependence between the Charter's action areas is not to mean that all actions should be taken at the point of

DOI: http://x.doi.org/10.4314/ejhs.v28i3.14 
time; rather, it is to mention that the effectiveness of the program depends on filling the vacuum by the action that closely fits $(41,42)$.

As professionals, we are not prescribing all the programs at the point of time with equal amount; rather, we tend to invite in order to apply those frameworks. Several authors in their systematic and comprehensive reviews indicated that behavioral and individual factors were the predictors of T2DM. This is comparable to Ottawa Charter making a supportive environment and building public health policy (27-37). For instance, Goodstadt et al., in his designed program considered as effective in some programs that stress one action area more than others but may not sufficient for fully implementing all the programs (43).

In our opinion and as indicated in the preceding reports, T2DM prevention requires more synergies with policy makers and behavioral health promotion scientists instead of the traditional approaches. This idea is similar to Baum and Fisher who believed to avoid chapter based methodological approaches and identify practical factors and ideological implications to convince governments to behavioral health promotion (44). There are several reasons why Ottawa Charter frameworks are not interlinked with various diseases prevention and not fully implemented, despite the evidence of their effectiveness $(40,44)$. This may be low implementing skills of managers and decision makers. Some others may perceive it as narrowing the reality than emerging philosophy.

As strength, this article provides health promotion professionals for ascertaining the extent of profession inauguration to different diseases prevention aspects. The article invites the next generation to avoid canonizing this issue: as is true of every heritage, the successors must decide on its use. As a limitation, even though contextualizing is a must to bring amicable change in disease prevention, the authors solely focused on reminding professional implantation of different from traditional approaches and health promotion strategies as primary prevention. In parallel speaking, the use of five actions of Ottawa Charter is still utilized with non-professional individuals who are less familiar with these concepts. The other limitation is that the applications of Ottawa Charter actions differ in different places owing to the various disease conditions, which, in turn, leads to failure to contextualize uniformly as intended.

To conclude, evidence showed that the most commonly used health promotion interventions in T2DM did articulate Ottawa Charter frameworks in various countries. Furthermore, since the current disease transition is from bacteria to behavior, all the risk factors are modifiable. Sticking to intervention by integrating health into all policies and expressing the issue of health communications is related to T2DM to Ottawa Charter is a writers' imperative. As field experts, we believe that applying all the basic principles of health promotion and the idea of Ottawa Charter articulation are the most important in disease prevention and behavior modification. Therefore, we recommend that field specialists figure out the problem of integration and to frame sounded policy integration through strong and long-term policy evaluation researches.

\section{ACKNOWLEDGMENTS}

The authors would like to acknowledge all staff members of the Department of Health Education and Health Promotion, School of Public Health, and International Campus of Tehran University of Medical Sciences for their unreserved administrative support during the writing of this manuscript. Special thanks should also go to Tehran University of Medical Sciences digital library for the provision of available search. 


\section{REFERENCES}

1. Kickbusch I. The contribution of the World Health Organization to a new public health and health promotion. American journal of public health. 2003;93(3):383-8.

2. WHO. Milestones in health promotion: Statements from global conferences. 2009.

3. Sindall C. Health promotion and chronic disease: building on the Ottawa Charter, not betraying it? : Oxford University Press; 2001.

4. Ståhl T, Wismar M, Ollila E, Lahtinen E, Leppo K. Health in all policies. Prospects and potentials Helsinki: Finnish Ministry of Social Affairs and Health. 2006.

5. Choukem SP, Kengne AP, Dehayem YM, Simo NL, Mbanya JC. Hypertension in people with diabetes in sub-Saharan Africa: revealing the hidden face of the iceberg. Diabetes research and clinical practice. 2007;77(2):293-9.

6. Bailey CJ, Day C. SGLT2 inhibitors: glucuretic treatment for type 2 diabetes. The British Journal of Diabetes \& Vascular Disease. 2010;10(4):193-9.

7. Zhou QP, Oh KM. Comparison of lifestyle behaviors and related factors between Asian American and white adults with prediabetes. Nursing \& health sciences. 2012;14(1):58-66.

8. Santosa A, Byass P. Diverse empirical evidence on epidemiological transition in lowand Middle-Income Countries: populationbased findings from INDEPTH network data. PloS one. 2016;11(5): 0155753.

9. Bakker K, Apelqvist J, Lipsky B, Van Netten J, Schaper N. The 2015 IWGDF guidance documents on prevention and management of foot problems in diabetes: development of an evidence-based global consensus. Diabetes/metabolism research and reviews. 2016;32(S1):2-6.

10. Murray CJ, Lopez AD. Alternative projections of mortality and disability by cause 1990 2020: Global Burden of Disease Study. The Lancet. 1997;349(9064):1498-504.
11. WHO. Ottawa charter for health promotion. First International Health Promotion Conference, Ottawa, Canada, 1986; 1986.

12. Harris N, Sandor M. Defining sustainable practice in community-based health promotion: A Delphi study of practitioner perspectives. Health Promotion Journal of Australia. 2013;24(1):53-60.

13. Vatannavaz E, Taymoori P. Factors Related in Mammography Screening Adoption: an Application of Extended Parallel Process Model. 2014.

14. Page-Reeves J, Mishra SI, Niforatos J, Regino L, Bulten R. An integrated approach to diabetes prevention: anthropology, public health, and community engagement. Qualitative report (Online). 2013;18:1.

15. Green J, South J. Evaluation: key concepts for public health practice. Open University Press: Maidenhead; 2006.

16. Hawe P, Degeling D, Hall J, Brierley A. Evaluating health promotion: a health worker's guide: MacLennan \& Petty Sydney; 1990.

17. Bauman A, Nutbeam D. Evaluation in a nutshell: a practical guide to the evaluation of health promotion programs: McGraw Hill; 2013.

18. Creswell JW, Clark VLP. Designing and conducting mixed methods research. 2007.

19. Johnson M, Jones R, Freeman C, Woods HB, Gillett M, Goyder E, et al. Can diabetes prevention programmes be translated effectively into real-world settings and still deliver improved outcomes? A synthesis of evidence. Diabetic medicine. 2013;30(1):3-15.

20. Infanti JJ, O'Dea A, Gibson I, McGuire BE, Newell J, Glynn LG, et al. Reasons for participation and non-participation in a diabetes prevention trial among women with prior gestational diabetes mellitus (GDM). $B M C$ medical research methodology. 2014;14(1):13.

21. Mcqueen DV, De Salazar L. Health promotion, the Ottawa Charter and 'developing personal skills': a compact history of 25 years. Health promotion international. 2011;26(suppl_2):ii194-ii201. 
22. Evans L, Hall M, Jones CM, Neiman A. Did the Ottawa Charter play a role in the push to assess the effectiveness of health promotion? Promotion \& education. 2007;14(2_suppl):2830.

23. Hills M, McQueen DV. At issue: two decades of the Ottawa Charter. Promotion \& education. 2007;14(2 suppl):5

24. García AA. Clinical and Life Quality Differences Between Mexican American Diabetic Patients at a Free Clinic and a Hospital-Affiliated Clinic in Texas. Public Health Nursing. 2008;25(2):149-58.

25. Knowler W, Barrett-Connor E, Fowler S, Hamman R, Lachin J, Walker E, et al. Reduction in the incidence of type 2 diabetes with lifestyle intervention or metformin. Scandinavian Journal of Medicine \& Science in Sports. 2003;13(3):208.

26. Tuomilehto J, Lindström J, Eriksson JG, Valle TT, Hämäläinen $\mathrm{H}$, Ilanne-Parikka $\mathrm{P}$, et al. Prevention of type 2 diabetes mellitus by changes in lifestyle among subjects with impaired glucose tolerance. New England Journal of Medicine. 2001;344(18):1343-50.

27. Van den Berg MH, Schoones JW, Vlieland TPV. Internet-based physical activity interventions: a systematic review of the literature. Journal of medical Internet research. 2007;9(3).

28. Foster C, Hillsdon M, Thorogood M, Kaur A, Wedatilake $\mathrm{T}$. Interventions for promoting physical activity. The Cochrane Library. 2005.

29. Sørensen M, Korsmo-Haugen H-K, Maggini M, Kuske S, Icks A, Rothe U, et al. Health promotion interventions in type 2 diabetes. Annali dell'Istituto Superiore di Sanità. 2015;51(3):192-8.

30. Thomas D, Elliott EJ, Naughton GA. Exercise for type 2 diabetes mellitus. Cochrane Database Syst Rev. 2006;3(3).

31. Duke SAS, Colagiuri S, Colagiuri R. Individual patient education for people with type 2 diabetes mellitus. The Cochrane Library. 2009.

32. Attridge $M$, Creamer J, Ramsden $M$, Cannings-John R, Hawthorne K. Culturally appropriate health education for people in ethnic minority groups with type 2 diabetes mellitus. The Cochrane Library. 2014.

33. Dorresteijn JA, Kriegsman DM, Assendelft WJ, Valk GD. Patient education for preventing diabetic foot ulceration. The Cochrane Library. 2014.

34. Dunkley AJ, Bodicoat DH, Greaves CJ, Russell C, Yates T, Davies MJ, et al. Diabetes prevention in the real world: effectiveness of pragmatic lifestyle interventions for the prevention of type 2 diabetes and of the impact of adherence to guideline recommendations. Diabetes care. 2014;37(4):922-33.

35. Aziz Z, Absetz P, Oldroyd J, Pronk NP, Oldenburg B. A systematic review of realworld diabetes prevention programs: learnings from the last 15 years. Implementation Science. 2015;10(1):172.

36. Sazlina S-G, Browning C, Yasin S. Interventions to promote physical activity in older people with type 2 diabetes mellitus: a systematic review. Frontiers in public health. 2013;1.

37. Furber S, Monger C, Franco L, Mayne D, Jones LA, Laws R, et al. The effectiveness of a brief intervention using a pedometer and step-recording diary in promoting physical activity in people diagnosed with type 2 diabetes or impaired glucose tolerance. Health Promotion Journal of Australia. 2008;19(3):189-95.

38. Hawe P, Wise M, Nutbeam D. Policy-and system-level approaches to health promotion in Australia. Sage Publications Sage CA: Thousand Oaks, CA; 2001.

39. Gruszin S, Hetzel D, Glover J. Advocacy and action in public health: lessons from Australia over the 20th century. Canberra: Australian National Preventive Health Agency. 2012.

40. Marks R. Health literacy and school-based health education: Emerald Group Publishing; 2012.

41. Jackson SF, Perkins F, Khandor E, Cordwell L, Hamann S, Buasai S. Integrated health promotion strategies: a contribution to tackling current and future health challenges. 
Health promotion international. 2006;21(suppl_1):75-83.

42. Jackson SF, Birn A-E, Fawcett SB, Poland B, Schultz JA. Synergy for health equity: integrating health promotion and social determinants of health approaches in and beyond the Americas. Revista Panamericana de Salud Publica. 2013;34(6):473-80.
43. Goodstadt MS, Hyndman B, McQueen D, Potvin L, Rootman I, Springett J. Evaluation in health promotion: synthesis and recommendations. WHO regional publications European series. 2001(92):517.

44. Baum F, Fisher M. Why behavioural health promotion endures despite its failure to reduce health inequities. Sociology of health \& illness. 2014;36(2):213-25. 